\title{
Exercise with 40-Hz light flicker improves hippocampal insulin signaling in Alzheimer disease mice
}

\author{
Seong-Hyun Kim ${ }^{1,2}$, Sang-Seo Park ${ }^{1,3}$, Chang-Ju Kim', Tae-Woon Kim ${ }^{4, *}$ \\ 'Department of Physiology, College of Medicine, Kyung Hee University, Seoul, Korea \\ ${ }^{2}$ Division of Global Sport Studies, College of Culture and Sports, Korea University, Sejong, Korea \\ ${ }^{3}$ School of Health and Kinesiology, University of Nebraska at Omaha, Omaha, NE, USA \\ ${ }^{4}$ Department of Human Health Care, Gyeongsang National University, Jinju, Korea
}

We examined whether exercise is associated with hippocampus-mediated improvement in insulin signaling and cell differentiation in the triple transgenic mouse model of Alzheimer disease ( $3 x \mathrm{Tg} A D$ ) murine model following exposure to $40-\mathrm{Hz}$ light flickering and exercise. We subjected 12-month-old 3xTg AD mice to exercise and $40-\mathrm{Hz}$ light flickering for 3 months. The exercise session was proceeded for 12 consecutive weeks with gradual increase of intensity. To investigate insulin signaling proteins, western blot was conducted to detect the ratio of phosphorylated insulin receptor $\beta$ ( $p$-IR $\beta$ )/total IR $\beta$ (t-IR $\beta$ ), phosphorylated insulin receptor substrate 1 (p-IRS-1)/total IRS-1 (t-IRS-1), phosphorylated phosphatidylinositide-3-kinase (p-PI3K)/total PI3K (t-PI3K), phosphorylated 3-phosphoinositide dependent protein kinase-1 (p-PDK1)/total PDK-1 (t-PDK1), phosphorylated protein kinase B (p-Akt)/total-Akt (t-Akt), and phosphorylated glycogen synthase kinase 3 beta (p-GSK3ß)/

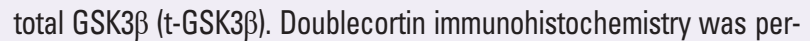
formed for assessing cell differentiation in the hippocampus. Treatments exerted a positive effect. The combination of exercise and $40-\mathrm{Hz}$ light flickering exposure was the most effective treatment enhancing insulin signaling. Increased ratio of $p-I R \beta / t-I R \beta, p-I R S-1 / t-I R S-1, p-P I 3 K / t-P I 3 K$, p-PDK1/t-PDK1, p-Akt/t-Akt, and p-GSK3 $/ \mathrm{t}-\mathrm{GSK} 3 \beta$ and enhanced cell differentiation were observed in the $3 x \operatorname{Tg} A D$ with exercise under $40-\mathrm{Hz}$ light flickering group. Our results indicate that exercise under $40-\mathrm{Hz}$ light flickering most potently improved insulin signaling, thereby promoted cell differentiation.

Keywords: Alzheimer disease, Exercise, 40-Hz light flicker, Insulin signaling, Hippocampus, Cell differentiation

\section{INTRODUCTION}

Alzheimer disease $(\mathrm{AD})$ is the most prevalent degenerative brain disorder. AD develops dementia over time and deteriorates cognitive abilities, particularly memory. Problems with memory linked to recent events occur in the early stages of $\mathrm{AD}$, along with changes in cognitive function such as language skills and judgment, eventually leading to the full loss of motor function (Kales et al., 2015). Synaptic alteration, structural and functional abnormalities in mitochondria, atypical inflammatory responses, extracellular amyloidbeta $(A \beta)$ plaque deposit, and intracellular neurofibrillary tangles are all linked to $\mathrm{AD}$ (Mattson, 2004). Reduction in $\mathrm{A} \beta$ clearance or overproduction can cause $A \beta$ accumulation in subcellular com- partments, impairs the organelle's function (Tanzi and Bertram, 2005).

Brain relies on glucose as its primary energy substrates and for sufficient glucose supply to the brain, and insulin signaling plays major role. Impairment of insulin signaling is major feature of type 2 diabetes and it is a risk factor for $\mathrm{AD}$, and these two diseases are linked by several common cellular and molecular processes. Furthermore, these two diseases also exhibit common aspects, such as glucose metabolism dysfunction and insulin resistant (Candeias et al., 2012). Insulin signaling is relevant to memory and cognition modulation, $A \beta$ precursor protein production and clearance, and cerebral glucose metabolism (Wu and Swaab, 2005). Disruption of brain insulin signaling causes the loss of memory functions due
${ }^{*}$ Corresponding author: Tae-Woon Kim (i) https://orcid.org/0000-0001-8832-0874 Department of Human Health Care, Gyeongsang National University,

33 Dongjin-ro, Jinju 52725, Korea

Email: twkim0806@gnu.ac.kr

Received: December 20, 2021 / Accepted: January 22, 2022
This is an Open Access article distributed under the terms of the Creative Commons Attribution Non-Commercial License (https://creativecommons.org/licenses/by-nc/4.0/) which permits unrestricted non-commercial use, distribution, and reproduction in any medium, provided the original work is properly cited. 
to AD (Candeias et al., 2012). The intraneuronal accumulating of neurofibrillary tangles caused by excessive hyperphosphorylation of extracellular deposition of $A \beta$ protein as senile plaques, and widespread neuronal mortality are all major neuropathological features of AD (Yang, 2019).

Since hippocampus, temporal lobe, and cerebral cortex have the highest levels of insulin receptor (IR) expression, these regions are the most susceptible to AD (Moss et al., 1990). In addition, the expression of additional downstream effectors such as phosphatidylinositide-3-kinase (PI3K), protein kinase B (Akt), and glycogen synthase kinase-3 (GSK-3) shows a pattern that resembles that of IR (Leroy and Brion, 1999). The significance of insulin signaling for synaptic function and the existence of active insulin signal transduction in brain areas intimately related with cognition. Furthermore, the hippocampus is one of the initial regions of the brain to be affected by these disorders (Gasparini et al., 2001).

Light therapy has been shown to improve sleep disturbances caused by neurodegenerative disorders such as Parkinson disease (Selkoe, 2001). A study revealed that using a 40-Hz light flicker can stimulate the production of gamma oscillation and reduce the A $\beta$ protein in the brain (Iaccarino et al., 2016). Previous studies have shown that regular exercise is beneficial to the brain's functioning and can be used in combination with drugs to prevent and treat AD (Adlard et al., 2005). In a study that used familial AD gene mutations, exercise minimized neurotoxicity caused by $\mathrm{AD}$ neuropathy. Also, exercise stimulates neuronal regeneration and contributes to an improvement in cognitive functioning through a reduction in beta-secretase activity, decreased accumulation of amyloid plaques and soluble $A \beta$ (Yuede et al., 2009). Therefore, this study investigated the effect of $40-\mathrm{Hz}$ light flickering and exercise on insulin signaling and cell differentiation in the hippocampus of triple transgenic mouse model of Alzheimer disease (3xTg AD).

\section{MATERIALS AND METHODS}

\section{Animals}

All mice experiments proceeded in accordance with the guidelines of the National Institutes of Health and the Korean Academy of Medical Science. The experimental protocol was approved by the Kyung Hee University Institutional Animal Care and Use Committee (approval number KHUASP [SE]-17-103). The animals were housed under conditions of controlled temperature $\left(24^{\circ} \mathrm{C} \pm 2^{\circ} \mathrm{C}\right)$ and lighting (07:00 a.m. to 19:00 p.m.) with food and water ad libitum. 15-month-old male wild type and triple transgenic ( $3 \mathrm{x} \mathrm{Tg}$ ) mice were randomly divided into a wild-type control group, a 3xTg AD group, a 3x'Tg AD exposed to $40-\mathrm{Hz}$ light flickering group, a $3 \mathrm{xTg} \mathrm{AD}$ with exercise group, and a $3 \mathrm{xTg}$ and exercise under $40-\mathrm{Hz}$ light flickering group $(\mathrm{n}=10$ in each group).

\section{Exercise protocol and $40-\mathrm{Hz}$ light flickering exposure time}

The 3xTg mice began exercising at the age of 12 months. The exercise groups exercised on a treadmill once daily in the dark, 6 days per week for 12 consecutive weeks. For adaptation, during the first 3 weeks, mice were given $5 \mathrm{~min}$ of warm up at $3 \mathrm{~m} / \mathrm{min}$, $30 \mathrm{~min}$ of main exercise at $10 \mathrm{~m} / \mathrm{min}$, and $5 \mathrm{~min}$ of cool down at $3 \mathrm{~m} / \mathrm{min}$ at $0^{\circ}$ incline. Subsequently, mice were subjected to $40 \mathrm{~min}$ of the main exercise at $11 \mathrm{~m} / \mathrm{min}$ for weeks 4 to $6,50 \mathrm{~min}$ of the main exercise at $12 \mathrm{~m} / \mathrm{min}$ for weeks 7 to 9 , and $50 \mathrm{~min}$ of the main exercise at $13 \mathrm{~m} / \mathrm{min}$ for the final weeks 10 to 12 . The exposure time of $40-\mathrm{Hz}$ light flickering was consistent with exercise time.

\section{Preparation of tissue}

Tissue preparation was proceeded. After the behavior test, the mice were sacrificed. For the brain slices, the mice were anesthetized with ethyl ether, perfused with $50 \mathrm{mM}$ phosphate-buffered saline (PBS), and then fixed with $4 \%$ paraformaldehyde in $100 \mathrm{mM}$ phosphate buffer $(\mathrm{pH}, 7.4)$. The brains were then removed, postfixed in the same fixative overnight, and transferred into a $30 \%$ sucrose solution for cryoprotection. Coronal sections with a thickness of $40 \mu \mathrm{m}$ were created using a freezing microtome (Leica, Nussloch, Germany).

\section{Immunohistochemistry}

Doublecortin (DCX) immunohistochemistry was performed, as the previously described method (Park et al., 2020). Immunohistochemistry was performed for DCX staining in the dentate gyrus to visualize cell differentiation. The sections were incubated in PBS for $10 \mathrm{~min}$ and then washed 3 times for $3 \mathrm{~min}$ in the PBS. Then incubated the sections in $1 \% \mathrm{H}_{2} \mathrm{O}_{2}$ for 15 to $30 \mathrm{~min}$. The sections were selected from each brain and incubated overnight with goat anti-DCX antibody (1:500; Santa Cruz Biotechnology, Santa Cruz, CA, USA) and then with biotinylated rabbit secondary antibody (1:250; Vector Laboratories, Burlingame, CA, USA) for another $90 \mathrm{~min}$. Vector Elite ABC Kit (Vector Laboratories) was used to amplify the secondary antibody. 3,3, diaminobenzidine substrate kit (Vector Laboratories) were used to visualize antibody-biotin-avidin-peroxidase complexes. The slides were air 
dried overnight at room temperature, and the coverslips were mounted using Permount.

\section{Western blotting}

Western blotting was performed, as the previously described method (Kim et al., 2020). Hippocampal tissues were homogenized on ice and lysed in lysis buffer. The protein content was measured using a colorimetric protein assay kit (Bio-Rad, Hercules, CA, USA). Thirty micrograms of protein were separated on sodium dodecyl sulfate-polyacrylamide gels and transferred on to a nitrocellulose membrane. Then, incubated with mouse $\beta$-actin (1:1,000; Santa Cruz Biotechnology), total IR $\beta$ (t-IR $\beta$ ) and phosphorylated IR $\beta$ (p-IR $\beta$ ) (1:1,000; Cell Signaling Technology, Danvers, MS, USA), total IR substrate 1 (t-IRS-1) and phosphorylated IRS-1 (p-IRS-1) (1:1,000; Cell Signaling Technology), t-PI3K and p-PI3K (1:1,000; Cell Signaling Technology), total 3-phosphoinositide dependent protein kinase-1 (t-PDK1) and phosphorylated PDK1 (p-PDK1) (1:1,000; Cell Signaling Technology), totalAkt (t-Akt) and phosphorylated Akt (p-Akt) (1:1,000; Cell Signaling Technology), total glycogen synthase kinase 3 beta (t-GSK3 $\beta$ ) and phosphorylated GSK3 $\beta$ (p-GSK3 $\beta$ ) (1:1,000; Cell Signaling Technology). Horseradish peroxidase-conjugated secondary antimouse antibodies were used for $\beta$-actin and horseradish peroxidase-conjugated secondary anti-rabbit antibodies were used for t-IR $\beta, \mathrm{p}-\mathrm{IR} \beta, \mathrm{t}-\mathrm{IRS}-1, \mathrm{p}-\mathrm{IRS}-1, \mathrm{t}-\mathrm{PDK}$, p-PDK, t-PI3K, p-PI3K, $\mathrm{t}-\mathrm{Akt}, \mathrm{p}-\mathrm{Akt}, \mathrm{t}-\mathrm{GSK} 3 \beta$, and $\mathrm{p}-\mathrm{GSK} 3 \beta$.

\section{Statistical analysis}

Cell counting and detected bands were quantified using ImagePro Plus (Media Cyberbetics Inc., Silver Spring, MD, USA) attached to a light microscope (Olympus, Tokyo, Japan). The data were analyzed with one-way analysis of variance, followed by the Duncan post hoc tests. All values are expressed as the mean \pm standard error of the mean, and $P$-values of $<0.05$ were considered significant.

\section{RESULTS}

\section{Effect of exercise with 40-Hz light flicker on the number of DCX-positive cells in hippocampal dentate gyrus}

Fig. 1 shows the number of DCX-positive cells in the hippocampus dentate gyrus. 3xTg AD group showed decreased DCXpositive cell number compared to wild-type control group $(P<0.05)$. In contrast, exercise or $40-\mathrm{Hz}$ light flicker significantly increased the number of DCX-positive cells compared to $\mathrm{AD}$ group $(P<0.05)$.
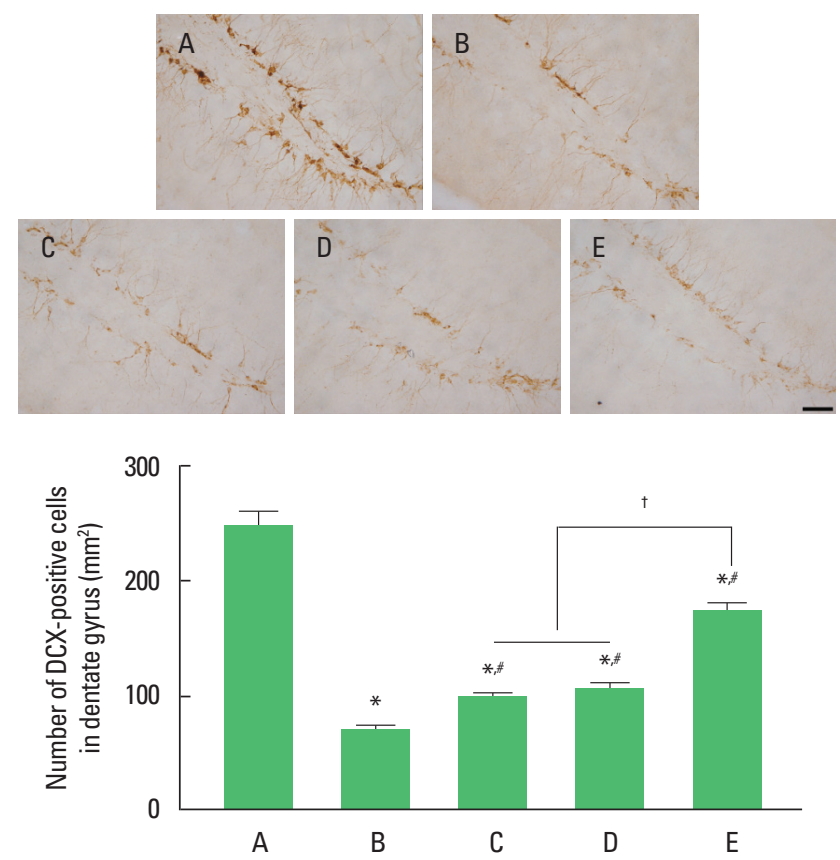

Fig. 1. Effect of exercise under exposure to 40-Hz light flicker on cell differentiation in hippocampus dentate gyrus. Upper panel: photomicrographs of doublecortin (DCX)-positive cells. The scale bar represents $50 \mu \mathrm{m}$. Lower panel: data of DCX-positive cells in each group. A, wild-type control (CON) group; $B$, triple transgenic mouse model of Alzheimer disease (AD) group; $C, A D$ exposed to $40-\mathrm{Hz}$ light flickering group; $D, A D$ with exercise group; $E, A D$ with exercise under 40 -Hz light flickering group. ${ }^{*} P<0.05$ compared to $\mathrm{CON}$ group. ${ }^{\#} P<0.05$ compared to $\mathrm{AD}$ group. ${ }^{\dagger} P<0.05$.

In the number of DCX-positive cells, 3xTg AD with exercise under 40-Hz light flickering group showed a significant increase compared to $3 \mathrm{xTg} \mathrm{AD}$ exposed to $40-\mathrm{Hz}$ light flickering group and $3 \times \mathrm{Tg} \mathrm{AD}$ with exercise group $(P<0.05)$, while there was no significant difference between $3 \mathrm{xTg} \mathrm{AD}$ exposed to $40-\mathrm{Hz}$ light flickering group and $3 \times \mathrm{Tg} \mathrm{AD}$ with exercise group.

\section{Effect of exercise with $40-\mathrm{Hz}$ light flicker on the ratio of $\mathrm{p}-\mathrm{IR} \beta / \mathrm{t}-\mathrm{IR} \beta$ and $\mathrm{p}-\mathrm{IRS}-1 / \mathrm{t}-\mathrm{IRS}-1$ in hippocampus}

For analysis of western blotting data, we set each cascade of the wild-type control group to 1.00. Fig. 2 shows the relative expression of $\mathrm{t}-\mathrm{IR} \beta / \mathrm{p}-\mathrm{IR} \beta$ and $\mathrm{t}$-IRS- $1 / \mathrm{p}-\mathrm{IRS}-1$ in the hippocampus dentate gyrus. The ratio of $\mathrm{p}-\mathrm{IR} \beta / \mathrm{t}-\mathrm{IR} \beta$ and $\mathrm{p}-\mathrm{IRS}-1 / \mathrm{t}-\mathrm{IRS}-1$ were significantly decreased in the $\mathrm{AD}$ group compared to those in the wild-type control group $(P<0.05)$. In contrast, exercise or $40-\mathrm{Hz}$ light flicker significantly increased the ratio of $\mathrm{p}-\mathrm{IR} \beta / \mathrm{t}-\mathrm{IR} \beta$ and p-IRS-1/t-IRS-1 compared to AD group $(P<0.05)$. In the ratio of $\mathrm{p}-\mathrm{IR} \beta / \mathrm{t}-\mathrm{IR} \beta$ and $\mathrm{p}$-IRS-1/t-IRS-1, $3 \mathrm{xTg}$ AD with exercise under $40-\mathrm{Hz}$ light flickering group showed a significant increase com- 

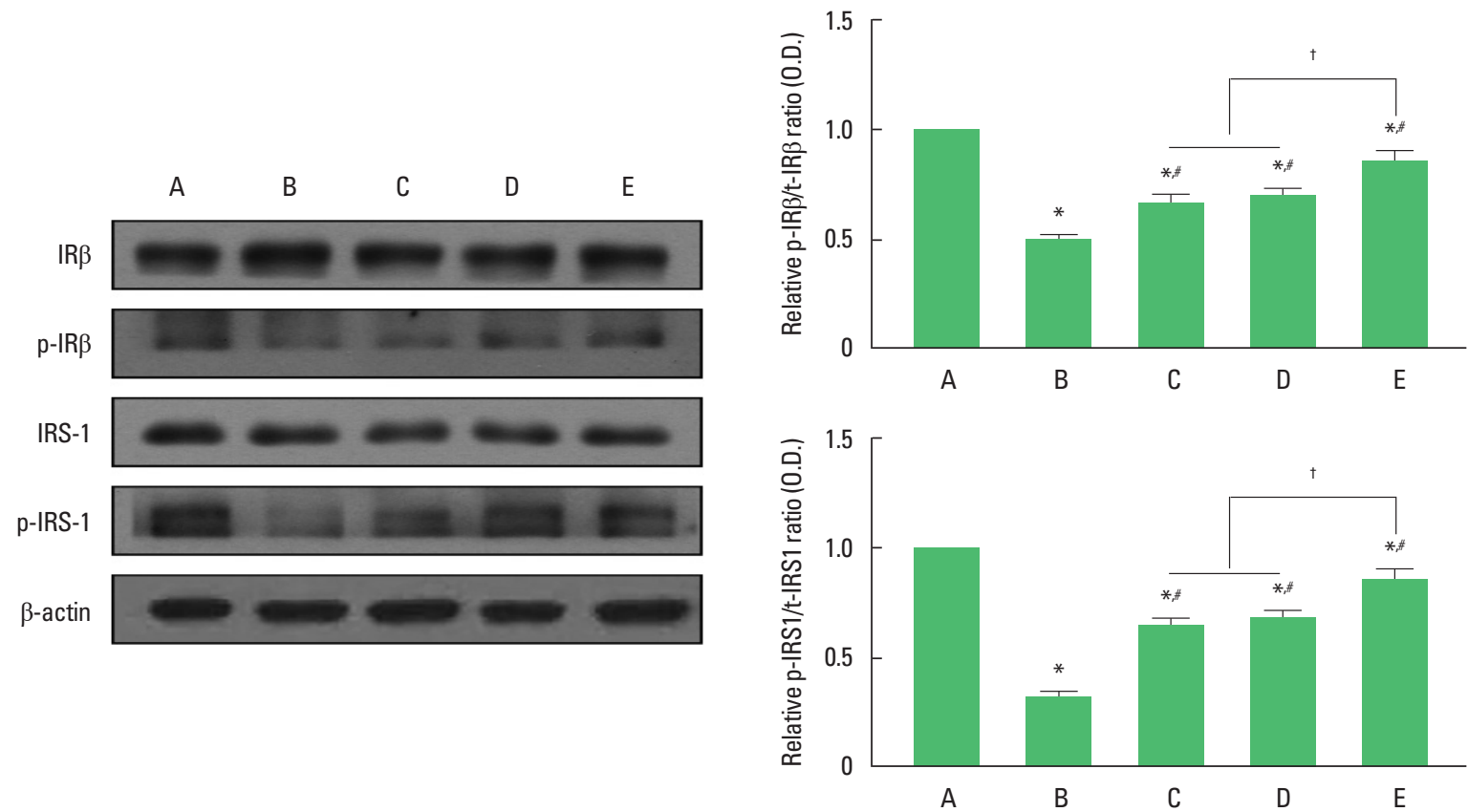

Fig. 2. Effect of exercise under exposure to 40-Hz light flicker on the expression of insulin receptor $\beta$ (IR $\beta$ ) and insulin receptor substrate 1 (IRS-1). Left panel: representative expression of IR $\beta$ and IRS-1. Right upper panel: ratio of phosphorylated IR $\beta$ (p-IR $\beta$ )/total IR $(\mathrm{t}-\mathrm{IR} \beta)$. Right lower panel: ratio of phosphorylated IRS-1 (p-IRS-1)/total IRS-1 (t-IRS-1). A, wild-type control (CON) group; B, triple transgenic mouse model of Alzheimer disease (AD) group; C, AD exposed to 40-Hz light flickering group; $D, A D$ with exercise group; $E, A D$ with exercise under $40-\mathrm{Hz}$ light flickering group. ${ }^{*} P<0.05$ compared to $C O N$ group. ${ }^{\#} P<0.05$ compared to $A D$ group. ${ }^{\dagger} P<0.05$.

pared to $3 \times \mathrm{Tg}$ AD exposed to $40-\mathrm{Hz}$ light flickering group and $3 \times \mathrm{Tg}$ AD with exercise group $(P<0.05)$, while there was no significant difference between $3 \times \mathrm{Tg}$ AD exposed to 40-Hz light flickering group and $3 \times \operatorname{Tg} \mathrm{AD}$ with exercise group.

\section{Effect of exercise with $40-\mathrm{Hz}$ light flicker on the ratio of p-PI3K/t-PI3K and p-PDK1/t-PDK1 in hippocampus}

Fig. 3 show the relative expression of t-PI3K/p-PI3K and t-PDK1/ $\mathrm{p}-\mathrm{PDK} 1$ in the hippocampus dentate gyrus. The ratio of $\mathrm{p}-\mathrm{PI} 3 \mathrm{~K} /$ t-PI3K and p-PDK1/t-PDK1 were significantly decreased in the $\mathrm{AD}$ group compared to those in the wild-type control group $(P<$ $0.05)$. In contrast, exercise or $40-\mathrm{Hz}$ light flicker significantly increased the ratio of $\mathrm{p}-\mathrm{PI} 3 \mathrm{~K} / \mathrm{t}-\mathrm{PI} 3 \mathrm{~K}$ and $\mathrm{p}-\mathrm{PDK} 1 / \mathrm{t}-\mathrm{PDK} 1 \mathrm{com}-$ pared to AD group $(P<0.05)$. In the ratio of $\mathrm{p}-\mathrm{PI} 3 \mathrm{~K} / \mathrm{t}-\mathrm{PI} 3 \mathrm{~K}$ and p-PDK1/t-PDK1, 3xTg AD with exercise under 40-Hz light flickering group showed a significant increase compared to $3 \times \mathrm{T} T \mathrm{AD}$ exposed to $40-\mathrm{Hz}$ light flickering group and $3 \times \mathrm{Tg} \mathrm{AD}$ with exercise group $(P<0.05)$, while there was no significant difference between $3 \times \mathrm{Tg}$ AD exposed to $40-\mathrm{Hz}$ light flickering group and $3 \mathrm{xTg} \mathrm{AD}$ with exercise group.

\section{Effect of exercise with 40-Hz light flicker on the ratio of p-Akt/t-Akt and p-GSK3//t-GSK3 $\beta$ in hippocampus}

Fig. 4 show the relative expression of p-Akt/t-Akt and p-GSK3ß/ $\mathrm{t}-\mathrm{GSK}-3 \beta$ in the hippocampus dentate gyrus. The ratio of $\mathrm{p}-\mathrm{Akt} /$ t-Akt and p-GSK3 $3 / \mathrm{t}-\mathrm{GSK} 3 \beta$ were significantly decreased in the $\mathrm{AD}$ group compared to those in the wild-type control group $(P<$ $0.05)$. In contrast, exercise or $40-\mathrm{Hz}$ light flicker significantly increased the ratio of $\mathrm{p}-A \mathrm{kt} / \mathrm{t}-\mathrm{Akt}$ and $\mathrm{p}-\mathrm{GSK} 3 \beta / \mathrm{t}-\mathrm{GSK} 3 \beta$ compared to $\mathrm{AD}$ group $(P<0.05)$. In the ratio of $\mathrm{p}-\mathrm{Akt} / \mathrm{t}-\mathrm{Akt}$ and p-GSK3 $3 / t-G S K 3 \beta$, 3xTg AD with exercise under 40-Hz light flickering group showed a significant increase compared to $3 \times \mathrm{Tg}$ $\mathrm{AD}$ exposed to $40-\mathrm{Hz}$ light flickering group and $3 \mathrm{xTg} \mathrm{AD}$ with exercise group $(P<0.05)$, while there was no significant difference between $3 x \operatorname{Tg} \mathrm{AD}$ exposed to $40-\mathrm{Hz}$ light flickering group and $3 \mathrm{xTg}$ AD with exercise group.

\section{DISCUSSION}

Insulin has neuromodulatory effects in various areas of the brain. Irregularity in insulin signaling pathway molecules was considered to have a role in the development of AD (Aleman et al., 2009). Insulin signaling initiates when insulin binds to and activates the 

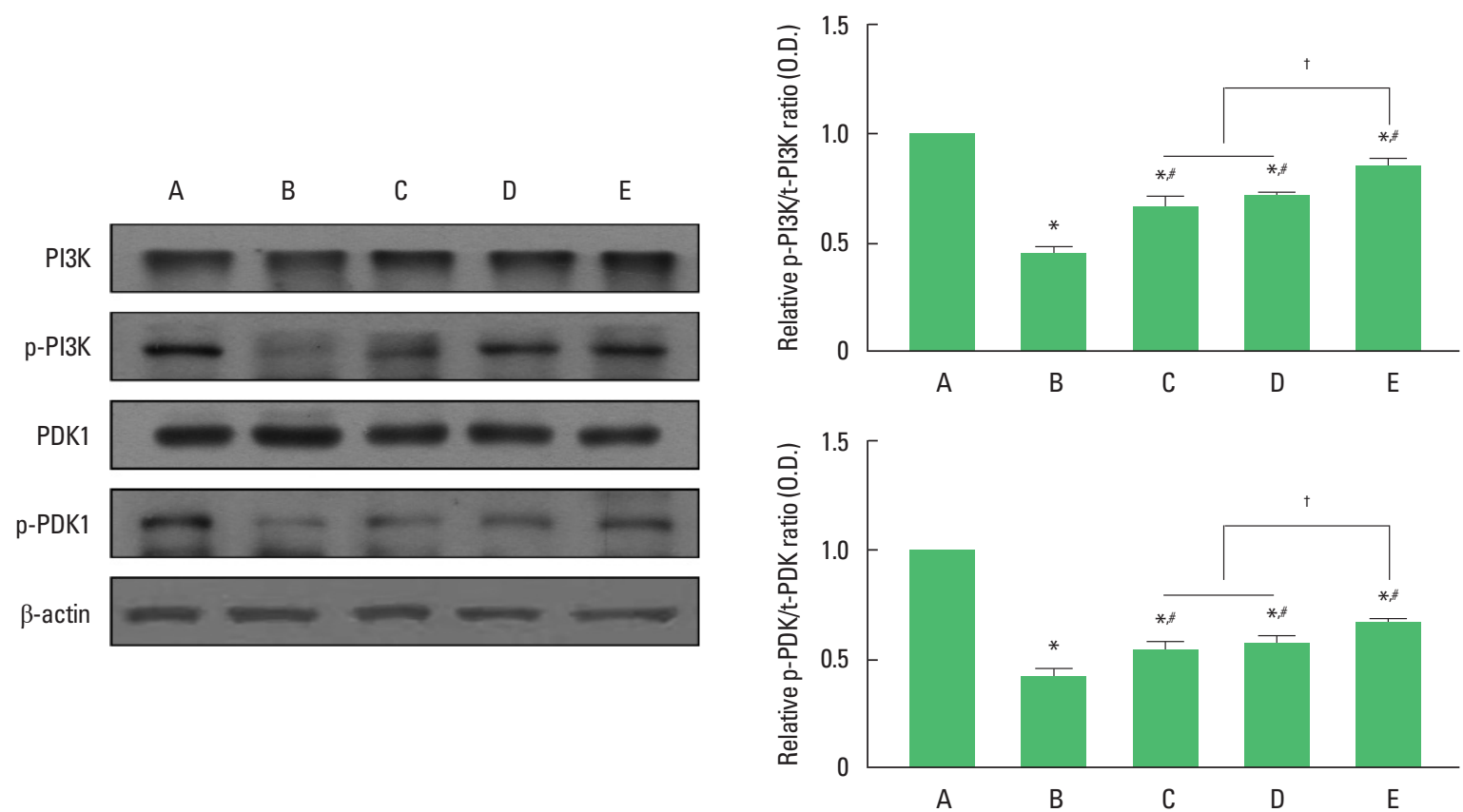

Fig. 3. Effect of exercise under exposure to 40-Hz light flicker on phosphatidylinositide-3-kinase (PI3K) and 3-phosphoinositide dependent protein kinase-1 (PDK1). Left panel: representative expression of PI3K and PDK1. Right upper panel: ratio of phosphorylated PI3K (p-PI3K)/total PI3K (t-PI3K). Right lower panel: ratio of phosphorylated PDK1 (p-PDK1)/total PDK1 (t-PDK1). A, wild-type control (CON) group; B, triple transgenic mouse model of Alzheimer disease (AD) group; $C$, AD exposed to 40-Hz light flickering group; $\mathrm{D}, \mathrm{AD}$ with exercise group; $\mathrm{E}, \mathrm{AD}$ with exercise under $40-\mathrm{Hz}$ light flickering group. ${ }^{*} P<0.05$ compared to CON group. ${ }^{*} P<0.05$ compared to $\mathrm{AD}$ group. ${ }^{\dagger} P<0.05$.
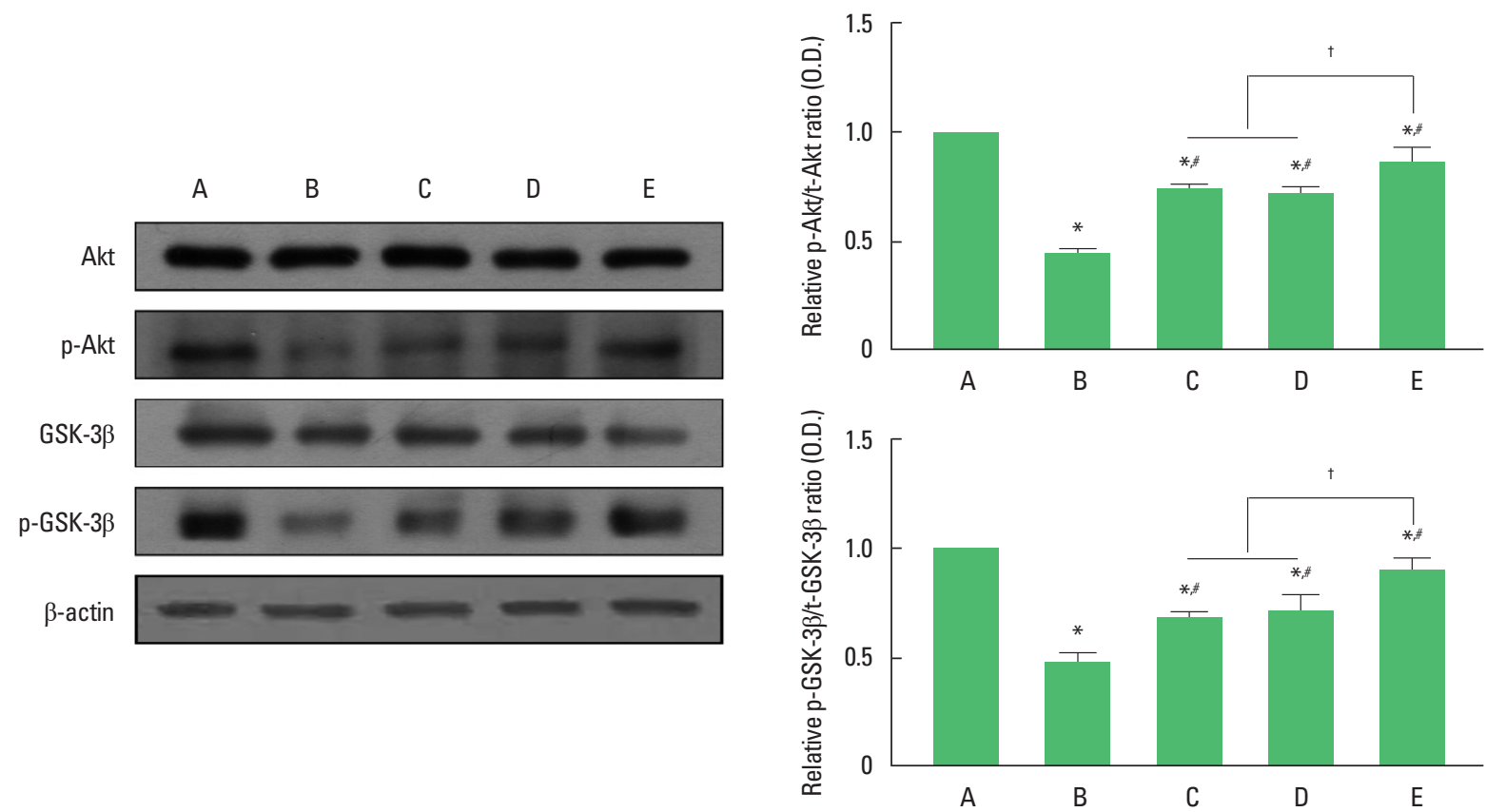

Fig. 4. Effect of exercise under exposure to 40-Hz light flicker on protein kinase B (Akt) and glycogen synthase kinase 3 beta (GSK3ß). Left panel: representative ex-

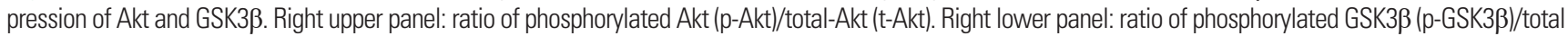
GSK3 $\beta$ (t-GSK3ß). A, wild-type control (CON) group; B, triple transgenic mouse model of Alzheimer disease (AD) group; C, AD exposed to 40-Hz light flickering group; $D, A D$ with exercise group; $E, A D$ with exercise under $40-\mathrm{Hz}$ light flickering group. ${ }^{*} P<0.05$ compared to CON group. ${ }^{\sharp} P<0.05$ compared to $A D$ group. ${ }^{\dagger} P<0.05$. 
IR, which causes additional substrates to be activated and phosphorylated. $A \beta$ has been reported to compete with insulin for IR binding and insulin binding affinity to IR is reduced as a result of this competition, resulting in insulin resistance (Xie et al., 2002). Previous research reported that low IRS-1, PDK1 was seen in AD. PDK1 is a kinase that facilitates in the stimulation of Akt phosphorylation and has been reported to be reduced in AD patients (Cen et al., 2007). Akt is involved in a variety of cellular activities, including metabolism, transcription, protein synthesis, neuron proliferation, growth, and survival. Decreased Akt gene has also been found in AD patients (Chen et al., 2012). GSK-3 is a serine/ threonine-specific protein kinase that participates in a variety of cell signaling pathways. GSK-3 has been discovered to be increasingly essential in cellular pathways such as insulin signaling, glycogenesis, neurotrophic factor signaling, neurotransmitter signaling (Ding et al., 2000). GSK-3 is activated by $A \beta$, causing tau protein phosphorylation, and tau overexpression leads to greater A $\beta$ plaque formation (Hernández et al., 2010). GSK-3 is blocked by GSK $3 \alpha$ or GSK $3 \beta$ phosphorylation of Ser 21 or Ser 9 and is enhanced in the lack of Akt activation (Townsend et al., 2007). Previous research has revealed that in the $3 \mathrm{xTg} \mathrm{AD}$ mice, the expression of $\mathrm{p}-\mathrm{GSK} 3 \beta$ and $\mathrm{p}-\mathrm{Akt}$ reduced while the expression of $A \beta$ elevated concurrently (Li et al., 2018). In the present study, the activation of insulin signaling pathway including IR and downstream proteins was decreased in $3 \times \mathrm{Tg}$ mice. Increased insulin resistance due to $A \beta$ disturbances downregulated the insulin signaling pathway.

Thus, insulin is an essential trophic element in brain development. Furthermore, the activation of insulin pathway controls neuroblast diffusion from quiescence (Sousa-Nunes et al., 2011). Insulin enhances neurogenesis by regulating neural stem cell proliferation, differentiation (Brooker et al., 2000). In our study, cell differentiation was significantly lower compared to wild-type control group. Because a sufficient supply of glucose cannot be established, the downregulation of insulin signaling in the hippocampus may impact cell differentiation. Furthermore, reduced activation of Akt may affect other cell signaling pathway and result in impairment of metabolism.

The 40-Hz light flicker stimulates the brain and restores gamma rhythms. In a mouse model of $\mathrm{AD}, 40-\mathrm{Hz}$ light flicker decreased $\mathrm{A} \beta$, resulting in memory improvements (Iaccarino et al., 2016; Singer et al., 2018). 40-Hz light flickering induced gamma oscillations in the visual cortex, hippocampus, and prefrontal cortex, improving spatial learning and memory as well as protein levels of various synaptic signaling and synaptic plasticity markers
(Adaikkan et al., 2019). In the present study, AD model exposed to $40-\mathrm{Hz}$ light flicker showed significant enhancement on insulin signaling and cell differentiation compared to AD group. Since $A \beta$ competes with insulin for IR binding (Xie et al., 2002), it is plausible to claim that reduced $A \beta$ by $40-\mathrm{Hz}$ light flicker ameliorates insulin signaling in $\mathrm{AD}$ hippocampus. In addition, increased p-GSK3 $3 / t$-GSK3 $\beta$ ratio may have mitigate the inhibition of cell differentiation as shown in our data.

Physical exercise has been reported to improve cell proliferation, differentiation, and neurogenesis (Boehme et al., 2011). Those who engage in regular physical activity have lower plasma $A \beta$ and brain amyloid levels (Brown et al., 2013). Thus, exercise has been shown to delay and protect against cognitive impairments by lowering $\mathrm{A} \beta$ and activating p-Akt and p-GSK3 $\beta$ (Ser 9) (Larson et al., 2006; Wang et al., 2019). Additionally, a previous study reported that exercise enhances the hippocampal insulin signaling pathway (Muller et al., 2011). In the present study, $A D$ with exercise group showed improvement on insulin signaling and cell differentiation compared to $\mathrm{AD}$ group. As with previous research results, exercise appears to lower insulin resistance and reduced $A \beta$ level to enable insulin signaling pathway. In addition, increased glucose metabolism and Akt activation may promotes cell differentiation and proliferation.

Park et al. (2020) reported that exercise under 40-Hz light flickering significantly lowered $A \beta$ in hippocampus, improved neurogenesis, reduced apoptosis and exhibit enhanced cognitive functions compared to each independent treatment in $3 \times \mathrm{Tg} \mathrm{AD}$ mice. In this study, AD exercise under 40-Hz light flickering group showed significant improvement in insulin signaling and cell differentiation. These results indicate that exercise combined with $40-\mathrm{Hz}$ light flickering may have synergetic effect on $\mathrm{AD}$ by reducing $A \beta$ and normalizing the metabolic pathway including insulin signaling.

\section{CONFLICT OF INTEREST}

No potential conflict of interest relevant to this article was reported.

\section{ACKNOWLEDGMENTS}

This work was supported by the Ministry of Education of the Republic of Korea and the National Research Foundation of Korea (NRF-2017S1A5B5A02025250). 


\section{REFERENCES}

Adaikkan C, Middleton SJ, Marco A, Pao PC, Mathys H, Kim DN, Gao F, Young JZ, Suk HJ, Boyden ES, Mchugh TJ, Tsai LH. Gamma entrainment binds higher-order brain regions and offers neuroprotection. Neuron 2019;102:929-943.

Adlard PA, Perreau VM, Pop V, Cotman CW. Voluntary exercise decreases amyloid load in a transgenic model of Alzheimer's disease. J Neurosci 2005;25:4217-4221.

Aleman A, Torres-Alemán I. Circulating insulin-like growth factor I and cognitive function: neuromodulation throughout the lifespan. Prog Neurobiol 2009;89:256-265.

Boehme F, Gil-Mohapel J, Cox A, Patten A, Giles E, Brocardo PS, Christie BR. Voluntary exercise induces adult hippocampal neurogenesis and BDNF expression in a rodent model of fetal alcohol spectrum disorders. Eur J Neurosci 2011;33:1799-1811.

Brooker GJ, Kalloniatis M, Russo VC, Murphy M, Werther GA, Bartlett PF. Endogenous IGF-1 regulates the neuronal differentiation of adult stem cells. J Neurosci Res 2000;59:332-341.

Brown BM, Peiffer JJ, Taddei K, Lui JK, Laws SM, Gupta VB, Taddei T, Ward VK, Rodrigues MA, Burnham S, Rainey-Smith S, Villemagne VL, Bush A, Ellis KA, Masters CL, Ames D, Macaulay SL, Szoeke C, Rowe CC, Martins RN. Physical activity and amyloid- $\beta$ plasma and brain levels: results from the Australian Imaging, Biomarkers and Lifestyle Study of Ageing. Mol Psychiatry 2013;18:875-881.

Candeias E, Duarte AI, Carvalho C, Correia SC, Cardoso S, Santos RX, Placido AL, Perry G, Moreira PI. The impairment of insulin signaling in Alzheimer's disease. IUBMB Life 2012;64:951-957.

Cen L, Hsieh F, Lin H, Chen C, Qualman S, Lin J. PDK-1/AKT pathway as a novel therapeutic target in rhabdomyosarcoma cells using OSU03012 compound. Br J Cancer 2007;97:785-791.

Chen LM, Xiong YS, Kong FL, Qu M, Wang Q, Chen XQ, Wang JZ, Zhu LQ. Neuroglobin attenuates Alzheimer-like tau hyperphosphorylation by activating Akt signaling. J Neurochem 2012;120:157-164.

Ding VW, Chen RH, McCormick F. Differential regulation of glycogen synthase kinase $3 \beta$ by insulin and Wnt signaling. J Biol Chem 2000; 275:32475-32481.

Gasparini L, Gouras GK, Wang R, Gross RS, Beal MF, Greengard P, Xu H. Stimulation of $\beta$-amyloid precursor protein trafficking by insulin reduces intraneuronal $\beta$-amyloid and requires mitogen-activated protein kinase signaling. J Neurosci 2001;21:2561-2570.

Hernández F, Gómez de Barreda E, Fuster-Matanzo A, Lucas JJ, Avila J. GSK3: a possible link between beta amyloid peptide and tau protein. Exp Neurol 2010;223:322-325.

Iaccarino HF, Singer AC, Martorell AJ, Rudenko A, Gao F, Gillingham
TZ, Mathys H, Seo J, Kritskiy O, Abdurrob F, Adaikkan C, Canter RG, Rueda R, Brown EN, Boyden ES, Tsai LH. Gamma frequency entrainment attenuates amyloid load and modifies microglia. Nature 2016;540:230-235.

Kales HC, Gitlin LN, Lyketsos CG. Assessment and management of behavioral and psychological symptoms of dementia. BMJ 2015;350:h369.

Kim TW, Park SS, Shin MS, Park HS, Baek SS. Treadmill exercise ameliorates social isolation-induced memory impairment by enhancing silent information regulator-1 expression in rats. J Exerc Rehabil 2020;16:227233.

Larson EB, Wang L, Bowen JD, McCormick WC, Teri L, Crane P, Kukull $\mathrm{W}$. Exercise is associated with reduced risk for incident dementia among persons 65years of age and older. Ann Intern Med 2006;144: 73-81.

Leroy K, Brion JP. Developmental expression and localization of glycogen synthase kinase-3 $\beta$ in rat brain. J Chem Neuroanat 1999;16:279293.

Li T, Jiao JJ, Hölscher C, Wu MN, Zhang J, Tong JQ, Dong XF, Qu XS, Cao Y, Cai HY, Qi JS. A novel GLP-1/GIP/Gcg triagonist reduces cognitive deficits and pathology in the 3xTg mouse model of Alzheimer's disease. Hippocampus 2018;28:358-372.

Mattson MP. Pathways towards and away from Alzheimer's disease. Nature 2004;430:63-69.

Moss AM, Unger JW, Moxley RT, Livingston JN. Location of phosphotyrosine-containing proteins by immunocytochemistry in the rat forebrain corresponds to the distribution of the insulin receptor. Proc Natl Acad Sci U S A 1990;87:4453-4457.

Muller AP, Gnoatto J, Moreira JD, Zimmer ER, Haas CB, Lulhier F, Perry ML, Souza DO, Torres-Aleman I, Portela LV. Exercise increases insulin signaling in the hippocampus: physiological effects and pharmacological impact of intracerebroventricular insulin administration in mice. Hippocampus 2011;21:1082-1092.

Park SS, Kim TW, Park HS, Seo TB, Kim YP. Effects of treadmill exercise on activity, short-term memory, vascular dysfunction in maternal separation rats. J Exerc Rehabil 2020;16:118-123.

Selkoe DJ. Alzheimer's disease: genes, proteins, and therapy. Physiol Rev 2001;81:741-766.

Singer AC, Martorell AJ, Douglas JM, Abdurrob F, Attokaren MK, Tipton J, Mathys H, Adaikkan C, Tsai LH. Noninvasive 40-Hz light flicker to recruit microglia and reduce amyloid beta load. Nat Protoc 2018;13: 1850-1868.

Sousa-Nunes R, Yee LL, Gould AP. Fat cells reactivate quiescent neuroblasts via TOR and glial insulin relays in Drosophila. Nature 2011;471: 508-512.

Tanzi RE, Bertram L. Twenty years of the Alzheimer's disease amyloid 
hypothesis: a genetic perspective. Cell 2005;120:545-555.

Townsend M, Mehta T, Selkoe DJ. Soluble A $\beta$ inhibits specific signal transduction cascades common to the insulin receptor pathway. J Biol Chem 2007;282:33305-33312.

Wang LR, Kim SH, Baek SS. Effects of treadmill exercise on the anxiety-like behavior through modulation of GSK3 $\beta / \beta$-catenin signaling in the maternal separation rat pup. J Exerc Rehabil 2019;15:206-212.

$\mathrm{Wu} \mathrm{YH}$, Swaab DF. The human pineal gland and melatonin in aging and Alzheimer's disease. J Pineal Res 2005;38:145-152.

Xie L, Helmerhorst E, Taddei K, Plewright B, Van Bronswijk W, Martins
R. Alzheimer's $\beta$-amyloid peptides compete for insulin binding to the insulin receptor. J Neurosci 2002;22:RC221.

Yang SH. Cellular and molecular mediators of neuroinflammation in Alzheimer disease. Int Neurourol J 2019;23:54-62.

Yuede CM, Zimmerman SD, Dong H, Kling MJ, Bero AW, Holtzman DM, Timson BF, Csernansky JG. Effects of voluntary and forced exercise on plaque deposition, hippocampal volume, and behavior in the Tg2576 mouse model of Alzheimer's disease. Neurobiol Dis 2009;35: 426-432. 